\title{
ПОДГОТОВКА ЭКСПЕРТОВ СИСТЕМЫ ВЫСШЕГО ОБРАЗОВАНИЯ И ПОВЫШЕНИЕ ИХ КВАЛИФИКАЦИИ
}

\section{TRAINING OF HIGHER EDUCATION SYSTEM EXPERTS AND IMPROVING THEIR QUALIFICATIONS}

\section{Ginzburg}

Summary: The purpose of this article is to train experts in the education system and improve their skills. In the process of working on the article, the following methods were used: analysis, synthesis, comparison, correlation, generalization, study of scientific literature on the research problem. The problem of education and professional development of experts in the education system requires special care and attention, encourages reflection on the current opportunities for professional development of experts and their preparation for professional practice. It takes time to become a good expert in the education system, but this is not the main factor of professional development. During their studies and subsequent years of professional activity, the expert gets experience, but it is not only on this that they must build their skills. Thus, professional development is a replenishment of knowledge and acquisition of new skills that become necessary in the dynamic and complex work of an expert in the education system.

Keywords: professional training, education, expert, readiness, training, training program.
Гинзбург Денис Александрович

AНОУ ИНОС - Институт Новых Образовательных Систем ginzburg@mail.ru

Аннотация: Целью данной статьи является подготовка экспертов системы образования и повышение их квалификации. В процессе работы над статьей были использованы следующие методы: анализ, синтез, сравнение, корреляция, обобщение, изучения научной литературы по проблеме исследования. Проблематика образования и профессионального совершенствования экспертов системы образования требует особой заботы и внимания, побуждает к размышлению 0 текущих возможностях профессионального развития экспертов и подготовки их к профессиональной практике. Стать хорошим экспертом системы образования требует времени, но это не самый главный фактор профессионального развития. Во время учебы и в последующие годы профессиональной деятельности эксперт приобретает опыт, но не только на нем он должен строить своё мастерство. Таким образом, профессиональное совершенствование представляет собой пополнение знаний и приобретение новых навыков, которые становятся необходимыми в динамичной и сложной работе эксперта системы образования.

Ключевые слова: профессиональное обучение, образование, эксперт, готовность, подготовка, программа обучения. нновация педагогического образования стала актуальной проблемой как в России, так и во всем мире, и ее цели и задачи нуждаются в пересмотре в соответствии с текущим и будущим контекстами. Вопросы, вытекающие из этого, включают в себя пересечение и связь между модернизацией образования и трансформацией общества в целом.

Российское общество продолжает испытывать политические, социально-экономические и духовные изменения. Преобразования последних десятилетий стало переосмысление путей повышения эффективности образования (Горшунова 2002). В связи с этим подготовка экспертов занимает особое место и играет основополагающую роль в модернизации российской системы образования. В свете трансформации общества это образование нуждается в пересмотре с учетом роли педагогического образования.

Реформа системы образования за последние 20 лет привела к появлению целого ряда законодательных и нормативных актов, в которых признавалась необходимость обновления образования. Что касается конкретно подготовки экспертов системы образования, то в 2014 году была принята «концепция поддержки развития педагогического образования», в которой подчеркивалось, что в основе реформы лежат начальная подготовка учителей, подготовка без отрыва от производства и профессиональная переподготовка (концепция, 2014).

В 2014 году Министерством образования и науки Российской Федерации был запущен крупный проект по модернизации педагогического образования. Его основной целью было обеспечение подготовки учителей в соответствии с профессиональным стандартом учителя и федеральными государственными образовательными стандартами общего образования [5].

На первом этапе проект модернизации направлен на преодоление существующих проблем образования, включая использование образовательных технологий; традиционные подходы в обучении и преподавании и отсутствие системы независимой оценки качества подготовки будущих профессионалов

Поэтому целью данной статьи является подготовка 
экспертов системы образования и повышение их квалификации.

В России, то все требования к конкретным уровням образования, профессиям, специальностям и направлениям определяются федеральным органом исполнительной власти, который выполняет функции органа, разрабатывающего национальную политику и нормативно-правовое регулирование в сфере образования. Эти требования отражены в федеральных государственных образовательных стандартах. Таким образом, в результате завершения подготовки эксперт системы образования должен обладать целым рядом компетенций: общекультурной (ОЦК), общепрофессиональной (ОЦК) и профессиональной (ПК).

Федеральный государственный образовательный стандарт устанавливает круг профессиональных компетенций, которыми должны обладать выпускник программ подготовки экспертов системы образования в России, и включает в себя 9 общекультурных компетенций, 6 общепрофессиональных и 14 профессиональных компетенций. Учебная программа образования разработана таким образом, чтобы обеспечить постепенное достижение этих компетенций [4].

Таким образом, все приобретенные будущими экспертами способности можно сгруппировать в две большие категории: способности к обучению и к взаимодействию. Они взаимосвязаны, но для удобства мы рассмотрим их отдельно.

Способность учиться - это самая важная способность в профессии эксперта системы образования. Она предполагает использование интеллектуального потенциала для решения профессиональных задач. Развитие этой способности означает умение управлять своим временем, планировать и управлять своей деятельностью, искать необходимую информацию, выбирать подходящие методы работы и эффективно сотрудничать с другими.

В данном контексте обычное значение обучения расширяется - это означает переход от простого обучения к системному обучению, которое включает в себя овладение различными общими социокультурными способностями (Марголис 2014).

Способность к взаимодействию также принципиально важна. В процессе подготовки будущие эксперты системы образования имеют возможность развивать отношения с сокурсниками и их преподавателями. Им нужно познакомиться с окружающими людьми, потому что в процессе своей профессиональной деятельности они неизбежно будут взаимодействовать и работать с очень разными людьми. Умение работать в команде очень важно для эксперта системы образования. Семинары и совместные задания способствуют развитию этой способности через развитие способности включать других в процесс работы над своими задачами; посредничать и разрешать конфликты; управлять временем и планировать свою работу; пересматривать и корректировать работу других; объединять ряд материалов и работ в один коллективный продукт [1, 8, 9].

Современная система подготовки экспертов системы образования призвана способствовать непрерывному развитию экспертов в соответствии с их уровнем образования, квалификацией и опытом.

Для профессионального становления экспертов в области образования как специалистов по экспертноконсультативной деятельности необходима квалифицированная подготовка и обучение с использованием качественных программ подготовки. Для создания таких программ необходимо широко исследовать соответствующий опыт зарубежных стран. Исследователи из разных стран уже сделали немалый вклад в исследование этой темы. Так, ее особенности, взятые в плоскости специфики мирового и региональных образовательных процессов, раскрываются в трудах отечественных исследователей (В.Г. Кремень, С.Н. Кучер, С.С. Татарченкова, Г.Н. Прозументова, С.Б. Перинов, В.А. Ясвин, О.С. Боднар, С.Л. Братченко, Е.А. Суханова и др.).

Для профессионального становления экспертов в области образования как специалистов по экспертной деятельности необходима квалифицированная подготовка и обучение с использованием качественных программ подготовки. Для создания таких программ необходимо широко исследовать соответствующий опыт зарубежных стран. Исследователи из разных стран уже сделали немалый вклад в исследование многих аспектов функционирования и развития экспертной деятельности в области образования разных стран (С.Ю. Батышев, А.М. Новиков, В.А. Романов, Г.М. Романцев, В.А. Сластенин, В.А. Федоров, Э.Ф. Зеер, Н.В. Кузьмина, С.Б. Серяков, А.И. Субетто, Е.Г. Юдин и др.).

Подготовку экспертов в области образования в зарубежных странах осуществляют учреждения, которые сопровождают процесс развития образования. Так, в Европе таким учреждением является Европейская Сеть (национальных) агентств гарантии качества образования - Европейская ассоциация по обеспечению качества в высшем образовании; в США - Институт политики в области высшего образования и Американское общество по контролю качества; в Великобритании - Агентство обеспечения качества высшего образования и Институт обеспечения качества Великобритании. В отличие от Европы и Америки, в Российской Федерации подготовку экспертов обеспечивают на базе университетов, которые и реализуют программы подготовки специалистов- 
экспертов в организациях разных уровней (федеральные, муниципальные, региональные) $[6,10]$.

Изучение имеющихся квалификаций системы высшего образования дает возможность сделать вывод, что подготовка в самих учреждениях высшего образования специалистов таких квалификаций, как «ведущий консультант по вопросам развития системы образования» и «эксперт в области образования» не ведется. Однако существует общепринятая практика подготовки таких специалистов в организациях, которые проводят исследования по вопросам оценки качества уровня образования. Примером может послужить деятельность такой организации как Европейская сеть агентств гарантии качества образования. Подготовка экспертов на её базе проводится в виде отдельных семинаров, которые знакомят будущих специалистов с тенденциями развития как национальной, так и общеевропейской систем образования. На семинарах акцентируется внимание на $[7,12]$ :

- анализе и понимании специфики процесса работы эксперта;

- содержании экспертного отчета;

- умении применять результат проведенной экспертизы.

По итогам освоения Программы будущие эксперты системы образования смогут:

- различать образовательные результаты разных субъектов образовательного процесса;

- различать оценочные инструменты, оценочные процедуры и формы фиксации результатов оценочных процедур:

- проводить экспертную оценку образовательного процесса, условий и образовательных результатов, а также формулировать рекомендации по исправлению выявленных недостатков в сторону усиления эффективности и качества общего образования;

- различать инспекцию и экспертизу, контроль и оценку, контроль и надзор, контроль и проверку как разное по отношению к деятельности образовательных организаций и их субъектов;

- построить программу действий эксперта в области оценки образовательной организации и ее субъектов;

- спроектировать и апробировать рабочую технологическую карту реализации системы оценки результатов и качества образования;

- проводить интерпретацию полученных данных в ходе различных оценочных процедур и на их основе составлять аналитические записки с целью дальнейшей коррекционной деятельности субъектов образовательной деятельности;

- составлять экспертные заключения на основе полученных данных в ходе оценочных процедур;

- получить образцы современных контрольно-измерительных материалов для оценки образовательных результатов 21 века;

- освоить информационно-образовательную среду адекватную для построения эффективной системы школьной оценки качества образования;

- получить опыт проведения образовательного аудита с целью экспертной оценки школьной системы оценки качества образования своей образовательной организации.

По итогам обучения участники освоения программы подготовки экспертов системы образования получают документ соответствующего образца с записью в документе «специалист в области оценки результатов и качества высшего образования».

\section{ЛИТЕРАТУРА}

1. Алексеев, Н.Г. Принципы и критерии экспертизы программ развития образования / Н.Г. Алексеев // Вопросы методологии. - 1994. - № 1-2. - С. 59-68.

2. Боднар, О.С. Подготовка экспертов по оценке деятельности научно-методических учреждений и общеобразовательных учебных организаций в сфере методического менеджмента: [тематический сборник работ] / 0.С. Боднар. - Ровно: РОІПП0, 2014. - 118 с.

3. Братченко, С.Л. Мир экспертизы и его возможные координаты / С.Л. Братченко // Экспертиза образовательных инноваций / Под ред. Г.Н. Прозументовой. 囚 Томск: Томский государственный университет, 2007. 囚С. 31-45.

4. Горбатов, Д.С. Практикум по психологическому исследованию / Д.С. Горбатов. - Самара: БАХРАХ-М, 2000. - 248 с.

5. Кремень, В.Г. Философия национальной идеи. Человек. Образование. Социум. / В.Г. Кремень. - М.: Грамота, 2007. \494 с.

6. Кучер, С.Н. Организационно-педагогические условия подготовки экспертов в системе дополнительного профессионального образования : дис. .... канд. пед. наук: 13.00.08 / Кучер Сергей Николаевич. - Барнаул, 2009. - 181 с.

7. Перинов, С.Б. Подготовка образовательных экспертов в современной России: основные подходы / С.Б. Перинов // Профессиональное образование. 2013. - № 10. - C. 3-5.

8. Arra. Report 2006. Evaluation of public universities and their faculties. Bratislava, 2006.

9. Ball, H., 2012. Rational humanism as a form of humanism corresponding to the challenges of modern times. In: professional education: pedagogy and psychology. Chenstokhova-Kyiv (93-108). ISSN 2083-2753.

10. Cooper D., Robertson I., Tingly G. Selection and recruitment of the personnel: technologies of testing and evaluation. - M.: LLC «Vershina», 2005. 
11. Court, S (2007) 'Reshaping academic work and the academic workforce in the UK', paper presented at SRHE Conference, 11-13 December, Brighton.

12. Fooler S.R, Huber V.L. Selection and recruitment of personnel // Human resources management / Under edit. Of M.Pool, M.Wardner.- SPb.: Piter, 2000. p. 846 861.

13. Frederickson, B.L. (2013) Positive emotions broaden and build, Advances in Experimental Psychology 47, 1-54.

14. Ilyin E.P. Differentiated psychology of professional activity. — SPb.: Piter, 2008.

15. Reichert, Sybille. Research Strategy Development Development and Management at European Universities. Brussels: EUA Publications, 2006. http://www.eua.be/ index.php?id=128\#c400.

16. Sheldrake J. Management theory: From Taylorism to Japanization- SPb.: Piter, 2001.

17. Slovak Government (2007): Návrh Inova?nej stratégie SR na roky 2007 a? 2013 - upravené nové znenie (Proposal for the Slvoak Innovation Strategy for period 2004-2013 - amended text), Bratislava, 14th March 2007. Reported on the European Commission's Website: http://www.proinnoeurope.eu/index. $\mathrm{cfm}$ ?fuseaction=nwev.NewsReader\&news $=72 \&$ lang $=E N \&$ ParentID $=52 \&$ topic $\mid \mathrm{D}=117$

18. Spenser L.M., Spenser S.M. Competencies at work.- M.: Hippo, 2005.

19. Tatur, Y.G. (2004). Competence in the structure of the quality model of training of specialists. Higher education today, 3, 20-26.

20. Tolochek V.A. Professional selection and psychological tests. - M.: S0 «Bayard», 2007.

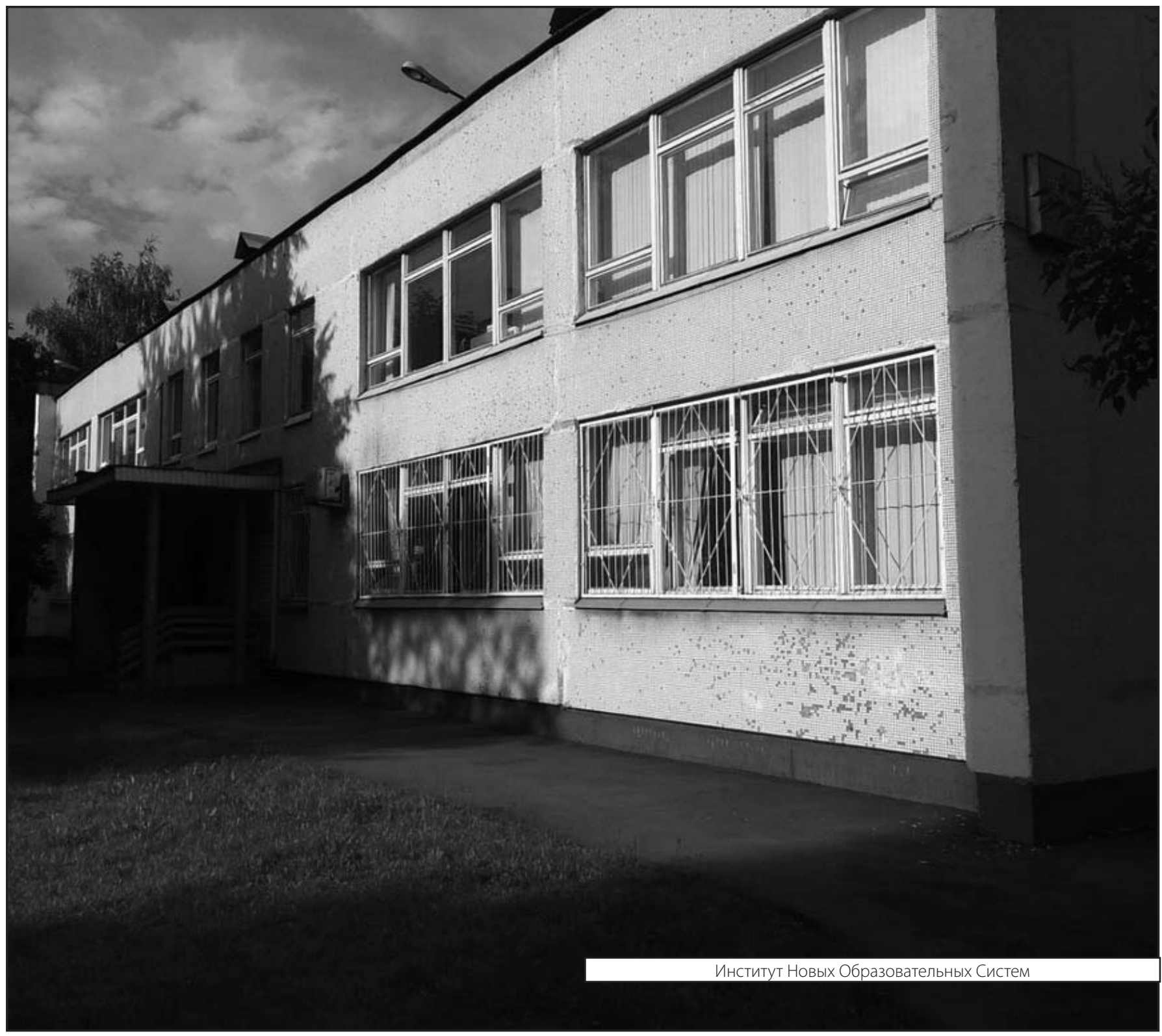

